\title{
AYDINLANMA TAHAYYÜLÜ VE BİR ÖDEV OLARAK TÜKETIM
}

\author{
Dr. Mustafa C. SADAKAOĞLU \\ İstanbul Aydın Üniversitesi \\ mustafasadakaoglu@aydin.edu.tr \\ https://orcid.org/0000-0002-4359-4828
}

\section{ÖZ}

$\mathrm{Bu}$ çalışmada modern toplumun kısa tarihinde özgül öneme sahip tüketim, tüketim toplumu, tüketim kültürü ve kitle kültürü kavramları üzerinden modernleşmenin değişen doğası kavranmaya çalışılmıştır. $\mathrm{Bu}$ amaçla, modernleşme ile kitle kültürü arasındaki karşılıklı ilişkinin doğası anlaşılmaya çalışılmıştır. Endüstriyel üretim olanaklarının yetkinleşmesiyle değişen toplumlar, yaşam biçimleri ve tüketim eğilimlerine dikkat çekilerek modernleşmenin bir tezahürü olarak değişen tüketim pratikleri çerçevesinde tüketim kültürünün politik ve normatif içeriği açıklanmaya çalış1lmıştır.

Anahtar Kelimeler: Kitle kültürü, tüketim, tüketim kültürü, modernizm, kapitalizm. 


\title{
IMAGINATION OF ENLIGHTENMENT AND \\ AN OBLIGATION OF COMPSUMPTION
}

\begin{abstract}
In this study, it was attempted to grasp the changing nature of modernization through the concepts of consumption, consumption society, consumption culture and mass culture with specific prefixes in the short history of modern society. For this purpose, the nature of the mutual relationship between modernization and mass culture has been tried to be understood. Attention to the changing societies, lifestyles and consumption trends with the competence of industrial production facilities tried to explain the political and normative contents of consumption culture in the context of changing consumption practices as a manifestation of modernization.
\end{abstract}

Keywords: Mass culture, consumption, consumption culture, modernity, capitalism

\section{Giriş}

Frankfurt Okulu ve Sosyal Araştırmalar Enstitüsü-Instituts für Sozialforschung (bundan sonra metin içinde Frankfurt Okulu olarak anılacak) üyelerince modernleşmenin tasfiye ettiği geleneksel toplumla başlayan karşılaştırmalı eleştirel kronoloji, yirminci yüzyılın ilk çeyreğinde yürürlüğe konulan Fordist üretim biçimince belirlenen bir dizi ekonomik örgütlenme ve aynı döneme denk gelen politikalardan kaynaklanan toplumsal değişmeleri anlama çabasıyla günümüze kadar sürmüştür. On dokuzuncu yüzyılın ikinci yarısından itibaren toplumsal yapıya nüfuz eden kısa modernleşme tarihinin üretimi yücelten doğası, yirminci yüzyılın ikinci yarısından itibaren kitlesel tüketimin özendirilmesiyle daha önce görülmemiş türden toplumsal karşılaşma ve örgütlenme biçimleri yaratmıştır. Tüketimin gündelik yaşam pratiği haline 
gelmesiyle biçim değiştiren toplumsal alan, içinde bulunduğumuz zaman diliminde bu kez "yurttaşlık ödevi" ve "toplumsal gereklilik" (elbette bir dizi ekonomik ve politik gelişmelerin de etkisiyle) benzeri nitelemelerle anılmaktadır. Bir yurttaşlık ödevi ve toplumsal gereklilik olarak tüketimin yaygın kabulü ya da toplumsal karşılığının bulunması, kitle kültürünün kuşatıcı etkilerine bağlanabilir. Ancak kitle kültürünü yaratan asıl kurucu özne, kültürel üretimin endüstriyel üretim mantığıyla mamul ediliyor olması olduğunu akılda tutmak gerekmektedir. Böylesine bir gereklilik, yirminci yüzyılın ikinci yarısından itibaren yürürlüğe konan ve kültürel üretimin sınırlarını belirleyen kültür politikalarının etraflıca irdelenmesini, kültürel üretimi mamul-metaya dönüştüren, şeyleştiren ve benzeştiren sürecin dikkatle irdelenmesini gerektirmektedir.

Frankfurt Okulu üyeleri (Max Horkheimer, Theodor Adorno) tarafindan üretim biçimi ve dağıtım olanakları bağlamında "kültür endüstrisi" olarak tanımlanan kültürel üretim ve tüketim süreçleri “yeni olanla eski olanı” başka bir nitelik ve bağlamda birleştirirken, yürürlüğe konan değişim ve dönüşüme tüketicinin uyumlu hale gelmesi beklenmektedir. Bir başka deyişle kültürel ürünlerin değişen üretim ve dağıtım biçimleri ürünün kendisiyle birlikte tüketicisini de dönüştürmektedir. $\mathrm{Bu}$ nedenle süreci tanımlamakta kullanılan "metalaşma", "şeyleşme" ve "fetişleşme" gibi kavramlar, kültürel üretim ile endüstriyel üretimin benzeşen doğasına iliş̧in bir dizi anıştırma içermektedir. Buna göre süreç; üretim ve tüketimi çizgisel bir hat üzerinde birleştiren, bunu yaparken her ikisini benzeştiren, standartlaştıran ve tek tipleştiren etkiler ve etkilenmelerde bulunmaktadır.

Walter Benjamin, Theodor Adorno, Max Horkheimer ve Herbert Marcuse gibi Frankfurt Okulu üyelerinin kitle kültürü ile tüketim toplumuna yönelik eleştirel bakış açıları, adı tüketim kültürü ve kitle kültürüyle birlikte anılan reklâm ve 
modanın üstlendiği önemli işleve göndermeler içermektedir. Gündelik pratiklerimizin merkezine yerleşen tüketim, tüketim toplumu, tüketim kültürü ve kitle kültürü gibi kavramların tartışılması, reklâm ve modanın toplumsal beğeni ve kabul oluşturma bağlamında oldukça önemli işlevler üstlenmiş olmasından kaynaklanmaktadır.

Kitle iletişimi, kitle kültürünün yaygınlaşması, benimsenmesi ve kabul görmesinde araçsal tamamlayıcı işlevi yerine getirmektedir. Tarihsel gelişim süreçleri dikkate alındığında gazete, radyo, televizyon ve sinemayla başlayan araçsal tamamlama, günümüzde yeni medya olanaklarını kullanarak yetkinleşme düzeyini mükemmelleştirmekte ve nüfuz etme gücünü bu sayede yeniden üretebilmektedir. Batılı akademik çevrelerin büyük bir bölümü tarafindan kitle kültürü ile kitle iletişimi (Golding, Murdock, 2000: 72) arasında bulunan organik bağ güçlü bir şekilde kabul görmekte ve paylaşılmaktadır. Buna göre kitle kültürü, meta üretimi mantığı ile benzer biçimde işleyen bir başka endüstri, kültür endüstrisi tarafından üretilen kültürel imgelerden beslenmekte, biçimlenmektedir. Kitle kültürünün sahip olduğu kuşatıcı etkinin kaynağında, kültürel ürünlerin taşınması ve yaygınlaşmasında kullanılan kitle iletişim araçlarının birey ve toplum üzerindeki nüfuz edici etkisi bulunmaktadır. Toplumsal pratikler üzerinden yapılan değerlendirmelerde gerçek ihtiyaçlarla sahte ihtiyaçlar arasında yapılan tercihlerin giderek daha fazla irrasyonel hale geliyor olması, eleştirel yaklaşımla irdelenen bir diğer konu başlığını oluşturmaktadır. Tüketicinin bireysel ayrıcalık kazanma ya da bireysel farkl11ık yaratabilme benzeri arzularından oluşan irrasyonel davranış kalıpları, tüketimin kitlesel mahiyetinin sürmesi için reklâm ve moda gibi araçlar kullanılarak canlı tutulmakta ve bir tür ihtiyaç yanılsaması yaratılmaktadır. Üretim ve tüketim süreçleri, bir ürünün üretim bandında başlayan ve tüketicinin satın alacağı market raflarında son bulan yolculuğu şeklinde basitçe tanımlanacak bir süreç olmaktan çıkmıştır. Aksine üretim ve tüketim süreçlerinin içinde bulunan 
çizgisel olmayan, çok özneli ve karmaşık ilişkiler nedeniyle bütünlük içinde kavranabilmesi güçleşmektedir. Dolayısıyla kitlesel üretim ve tüketim süreçleri, ürün tüketiciye ulaşıncaya değin somut ve belirgin süreçler kadar soyut ve kültürel tahayyüller tarafından da biçimlendirilmektedir. Böylece basitçe bir ürün olarak ele alındığında örneğin bir palto, yağmurdan ya da soğuk havadan koruyan kullanım değeri yanı sıra palto üzerinden özendirilen kimlik ve bu bağlamda harekete geçirilen arzuları kapsayan bir dizi kabul, özendirme ve yücelmeyle tüketim sürecine dâhil edilmektedir. Kitle kültürü ile tüketim kültürü arasında birbirinden beslenen karşılıklı ilişkinin kaynağında, geleneksel ile modern karşıtlığının tarihsel öznesi aydınlanma geleneği ile ortaya konan idealler bulunmaktadır. Modern olmanın çerçevesini belirleyen ekonomik, politik ve kültürel tezahürlerde göze çarpan en temel görüngü kullanılan metodolojinin büyük oranda aydınlanma geleneğinden besleniyor oluşudur. Aydınlanma, bir dizi ideal ve yöntem ortaya koyarak geleneksel olanın tasfiyesi ve modern olanın tasfiye edilen yerine konmasıyla kendini tanımlamaktadır. Aydınlanmanın idealize ettiği modernleşme tahayyülünde geleneksel toplumu esir alan dogmalardan kurtuluş ve efsanelerden özgürleşme vaadi bulunmaktadır. Aksi halde modern toplum, ne yarı insan yarı tanrılar ne de Hiristiyan teolojisi tarafindan kurulabilirdi. Modern toplum ancak ve mutlaka insan ve insanın özgürce kullanacağı aklı sayesinde var olacaktır.

$\mathrm{Bu}$ yazıda endüstriyel üretim tekniklerinin yetkinleşmesi bağlamında kitlesel üretim, kitlesel tüketim, tüketim kültürü ve tüketim toplumu gibi bir dizi kavramdan oluşan gündelik tüketim pratiği ele alınmıştır. Gündelik tüketim pratiklerinin zaman içinde dönüşmesi ve normatif anlam yüklenerek bir çeşit yurttaşlık ödevi haline gelmesi tartışılması amaçlanmaktadır. 


\section{Aydınlanma İdeallerinin Reddi: Kitle Külttürü Eleştirisi}

Frankfurt Okulu'nun sosyal bilimlere ilişkin üç ana ilgi alanı Tom Bottomore tarafindan şöyle tarif edilmektedir (1997: 61):

(1) Sosyal bilimlerde pozitivizmin epistemolojik ve metodolojik eleştirisi.

(2) Teknokratik-bürokratik egemenlik biçiminin oluşumunda bilim ve teknolojinin ideolojik etkisi.

(3) Kültür endüstrisi ya da genel olarak tahakkümün kültürel boyutlarının çözümlenmesi.

Bilimsel yöntem, teknik gelişme ve akıl üzerinden kendini tanımlayan aydınlanma, kendisinden önceki geleneksel toplumlarıysa zincire vurulmuş düşünceleri ve eski yaşam biçimleri nedeniyle kıyasıya eleştirmekteydi. $\mathrm{Bu}$ yönüyle "dogmaların zincirine vurulmuş" aydınlanma ideali; akıl, bilim ve tekniğin olanaklarını sonuna kadar kullanmayı önermekte ve ayrıcalıklı bir konum yüklediği insanoğluna özgürlük vaat etmekteydi.

Eleştirel kuram; aydınlanma tarafindan vaat edilen kurtuluş ve özgürleşme bir yana, aydınlanmanın önerdiği modern yaşam biçimlerinde bulunan egemenlik ilişkilerinde saklı tahakküm potansiyeli nedeniyle aydınlanmayı eski ve köhnemiş olarak tanımlamaktadır (Adorno, Horkheimer, 1995;19-63). Bu nedenle Adorno'nun nazarında aydınlanma metodolojisinin öngördüğü şekliyle, insan özgürlüğünün temeline aklı koymakla dinamit koymak arasında hiçbir fark yoktur çünkü nicel ve ölçülebilir yöntemlerle hesaplanabilir olana büyük önem atfeden aydınlanma metodolojisi; bu sayede önce doğa, ardından insan üzerinde kurduğu egemenlik nedeniyle bir dizi "felaketin yolunu" açmıştır. Buna göre insanoğlunun yüzyıllar boyunca karanlığa gömülmesine neden olan efsane ve dogmalardan kurtuluş vaadiyle yola çıkan aydınlanma ideali; 
insanoğlunu, insani olmayan kurallarca belirlenmiş yeni bir totaliterliğe teslim olmaya zorlamaktadır (Larrain, 1995: 80-81).

Eleştirel kuram tarafından aydınlanmaya yöneltilen bir diğer eleştiri; aydınlanmanın nicel değerlendirmeye özel önem atfeden metodolojisidir. Aydınlanmanın ölçen, hesaplayan ve sınıflandıran niceliğe dayalı yöntemleri insana özgü nitelikler ya da insana özgü farkl11ıkları dikkate almamakta ve insanı, matematiksel kesinlikte benzeştirmekte, tek tipleştirmekte ve aynılaştırmaktadır. Eleştirel kuramda modernlik meselesi bağlamında tartışılan bireyin şeyleşmesi ve nesne durumuna indirgenmesi ile toplumsal aynılaşma, Foucault'un bireyin ölümü üzerinden metaforize ettiği "modern teknoloji" eleştirisinin öncüsü gibidir. Foucault tarafindan modernleşmenin bir tezahürü olarak kavranan bireyin ölümü, birey ve toplumun modern teknolojiler tarafından teslim alınarak nesne konumuna indirgenmesine işaret etmektedir (Aktaran: Best ve Kellner, 1998: 263-64). Aydınlanma metodolojisinin günümüzde ne anlama geldiğini "mutluluk" kavramı üzerinden sorgulayan Jean Baudrillard (1997: 53-55)'a göre mutluluk ve eşitlik kavramlarını karşılaştırdığı düşünce sistematiğinde her iki kavramın etimolojik, tarihsel ve toplumsal bağlamda ideolojik bakımdan birbirinden benzediği, birbirinden beslendiği sonucuna varmaktadır. Modern toplumla birlikte eşitlik ve mutluluk kavramları arasındaki ilişki dönüşmüş ve eşitlik kavramı etrafında üretilen söylemin sahip olduğu güçlü içerik yerini mutluluğa bırakmıştır. Mutluluk kavramı da güçlü bir ideolojik içeriğe sahiptir. Ancak mutluluk kavramsallaştırması (tercih edildiği şekliyle); nesneler, imgeler, göstergeler ve konfor gibi ölçülebilir, sınıflandırılabilir başlıklarla sınırlı tutulmuştur. Oysa mutluluk kavramının öteki yarısı ölçülebilen kanıtlara ihtiyaç duymaz; "iç mutluluk-huzur" söz konusu olduğunda kitle kültürü ve tüketim toplumu tarafından dışlanmaktadır. Aydınlanma metodolojisi, modern toplumdan tüketim toplumuna geçişle 
birlikte ideal mutluluğun ölçülemeyen öteki yarısını sınıflandırılamadığı, nesnel ölçü ve ölçütlerce test edemediği için yok saymaktadır.

Eleştirel kuram içinde ele alınan kültürel çalışmalar ve kültür eleştirisi başlığı, kültür endüstrisi ile kitle kültürüne ilişkin bir dizi açıklama, kavramsallaştırma ve tanım içermektedir. Kültür endüstrisi kavramına ilk kez Adorno ile Horkheimer tarafından birlikte kaleme alınan "Aydınlanmanın Diyalektiğı”" içinde değinilmiştir. Yazarlara göre kültür eleştirisi; modern dünya, toplum ve ilişkilerin çok boyutlu ve karmaşık doğasını anlamakta artık ekonomik ve politik çıkarımların yetersiz kalıyor oluşundan kaynaklanan bir zorunluluktur. Bu noktada kültür eleştirisi, büyük oranda yapısal örgütlenmesini tamamlamış olan kapitalizmin toplumsal ilişkilerde kullandığg ikna ve tahakküm süreçlerini ele almakta ve bu süreçlerin hangi tür kültürel politikalarla desteklediğine ilişkin soruların peşine düşmektedir (Adorno, Horkheimer, 1995: 19-63).

Kitle kültürü ve kültür endüstrisine ilişkin eleştiriye temel olacak kimi belirti ve bulgular her ne kadar yirminci yüzyılın başından itibaren Avrupa ve Almanya'da görülmüş olsa da, bunların daha görünür ve somut kanıtlarla desteklenmesi Frankfurt Okulu üyelerinin ABD deneyimleriyle tamamlanmıştır. Almanya'da nazizmin iktidara gelmesi ve artan baskılar üzerine 1934 y1lında aralarında Max Horkheimer, Thedor W. Adorno, Herbert Marcuse, Leo Löwenthal ile Erich Fromm'un bulunduğu Frankfurt Okulu üyeleri, sığınmak zorunda kaldıkları ABD'de deneyimledikleri gündelik yaşam sayesinde kitle toplumu, kültür endüstrisi ve tüketim toplumu hakkında ilk sistematik çalışmaları yapabilmişlerdir. Bunun nedeni; yirminci yüzyılla birlikte başta $A B D$ ve Avrupa'da eğlencenin endüstrileşmesi, kültür ürünlerinin üretiminde kullanılan yöntemler ve kültürel tüketimin standartlaşması ilk akla gelen somut başlangıç noktalarıdır. Buna göre kültür ürünleri pazarın koşullarına uyumlanarak kitlesel tüketim ve kar amacıyla üretilmektedir. Pazar koşulları 
tarafından belirlenen kültür ürünleri, sadece tüketilmekle kalmayıp, ürünle birlikte dolaşıma sokulan normatif dünya tahayyülü tüketiciye telkin edilmektedir. Marcuse'ye göre bu durum tam anlamıyla tek boyutlu düşünce ve davranış önerisidir (1997: 27). Bu nedenle Frankfurt Okulu üyelerine göre kültür endüstrisinin dikkat çekilmesi gereken yanı, kültürden çok endüstriyel yan1, endüstri oluşudur (Adorno, Horkheimer, 1996:7). Nitekim Adorno (2003: 78)'nun kültür endüstrisi bağlamında ortaya koyduğu eleştirel düşünce sistematiğinde, kültürel ürünlerin üretim ve dağıtım sürecinden çok tek tipleştirilmesi ve tüketici üzerindeki standartlaştırıcı etkileri bulunur.

ABD'deki popüler müziğin üretim ve tüketim biçimlerini ele alarak açılamaya giriştiği kültür endüstrisi kavramını genişleten Adorno, tekniğin olanaklarıyla yeniden üretilen kültürel imgelerin modern toplumu her geçen gün daha fazla rasyonel hale getirdiğini savunmaktadır. Endüstriyel yöntemlerce belirlenen usullerde üretilen kültürel imgeler bu sayede yaşamın tüm alanlarına nüfuz edebilmektedir. Oysa önerdiği biçim ve içerik aracılığıla dünyanın nasıl işleyeceğine ilişkin bir dizi normatif önermelerde bulunan kültürel imgeler Adorno'ya göre "Vaat ettiklerini yerine getirmeyerek sahte tatminler dağıtmakta ve insanları kandırmaktadır." Sanat eseri, "çileci ve utançsızdır" oysa kültür endüstrisi, "pornografiktir ve iffet taslamaktadır." (Lunn, 1995: 187-201). Kültür endüstrisi, kendiliğinden ortaya çıkan bir kültür sorunu ya da popüler sanatın çağdaş bir formu değildir. Aksine kültürel üretimin kar dürtüsüyle üretilen standartlaştırılmış mallara dönüştürülmesidir. Adorno'nun kültür endüstrisine ilişkin kötümser bakış açısının kaynağında ABD deneyimleri deneysel bir araştırma, toplumsal tutum ve kanaatlerin kendiliğinden oluştuğu, ürünlerin niteliğini belirleyenlerinse tüketiciler olduğunu iddia etmektedir. Adorno'ya göre araştırmanın sonucu, önceden belirlenmiş ticari beklentileri doğrulamaktan başkaca bir şey değildir. Oysa yönlendirilen arzular, deneyimlerin kendiliğinden oluşmasına olanak vermemektedir; "izleyenlerin 
vereceği tepkiler önceden belirlenmişti ve aygıt tarafindan verilen emirler içselleştirilmekteydi” (Lunn, 1995: 259). Adorno kitle kültürü ile kültür endüstrisi kavramları arasında yaptıkları tercihin nedenini şöyle açıklamaktadır: "Müsveddelerimizde kitle kültüründen söz ediliyordu. Burada, kitlenin içinden adeta kendiliğinden yükselen bir kültür, halk sanatının günümüzdeki biçimi söz konusuymuş gibi konuyu savunanların hoşuna gidecek bir yorumu en baştan olanaksızlaştırmak için kitle kültürü ifadesini kültür endüstrisiyle değiştirdik.” (Adorno, 2014;109). Kültürel üretimin endüstri üzerinden tanımlanmasının en önemli nedeni geleneksel topluma özgü kültürel yaratıcılık ve çeşitliliğin, modern toplumun endüstriyel üretim yöntemlerince tek tipleştirilme tehdidi altında bulunuyor olmasıdır. Bu bağlamda kültür endüstrisi ve kitle kültürü kavramları arasındaki dolayım, üretimin bilimsel örgütlenmesinin bir sonucu olduğu kadar kültürel ihtiyacın karşılanmasında içerik, biçim ve dağıtım tekniklerinin tüketenler yerine üretenler tarafından belirleniyor olmasından kaynaklanmaktadır. Dolayısıyla aydınlama idealleri ile aydınlanma ideallerinin yarattığı fiili durum arasındaki tutarsızlığın kültürel ara yüzünde; teknik olanakların yetkinleşmesi, kitlesel üretim, dağıtım ve tüketimde kullanılan yöntemlerin kitlesel kültür üretim ve tüketiminde kullanılan yöntemlerle aynı olması bulunmaktadır.

Kültürel üretim biçiminin değişmesi ve toplumsal tezahürleri Walter Benjamin'in de ilgi alanı içinde bulunmaktadır. Benjamin, eleştirisini Adorno'nun aksine sanatsal üretimde endüstriyel yöntemler kullanılmasının tek tipleştirici etkisi yerine, geleneksel sanat ve sanatçının kaybettiği "aura-hale" metaforuyla kutsallığın kaybı üzerinden geliştirmiştir. Eleştirinin odağında kaybedilen kutsallığın bulunması ilk bakışta geleneksel topluma yönelik romantik bir özlem olarak değerlendirilmiş olsa da, Benjamin (Benjamin, 2000: 45-51)'in kültür endüstrisi eleştirisinde kullandığı metaforlar, modernleşmeyle birlikte sanat eserinin şimdi ve buradalığı ile biricik ve hakikiliğinin yok 
olmasına gönderme yapmaktadır. Gerçekten de tekniğin olanaklarıyla yeniden üretilebildiği çağda sanat yapıtı bu nitelikleri kaybetmekle kalmaz, hakiki oluşunu da koruyamaz artık. Yeniden-üretim tekniği, yeniden-üretilmiş olanı geleneğin alanından koparıp almakta, çoğaltmakta ve bir defaya özgü varlığı yerine kitlesel varlığını geçirmektedir (Benjamin, 2000: 55). Oysa sanat yapıtının hakiki oluşu, benzersiz özne oluşundan kaynaklanmaktadır ancak yeniden çoğaltılabilir, üretilebilir olmak sanat yapıtını amorf bir nesne haline dönüştürmektedir. Hakiki özne olmak yerine amorf bir nesneye dönüşen çoğaltılmış bir sanat yapıtı, ilk olarak kutsiyetini kaybetmektedir. Baudrıllard'da sanatsal üretim bağlamında aynı mesele "gerçekle kopan ilişki" üzerinden ele almaktadır. Buna göre (Baudrillard, 1991;74); bizatihi gerçeğin kaybedildiği bir simülasyon evreninde peşine düşülecek son şey sanatsal üretimin gerçekle kurduğu bağ olmalıdır. Sanat, gücünü kaybetmiştir. Diğer yandan teknik yetkinleşmeyle teçhiz edilen kitlesel üretim, ürettiklerini şeyleştirmekle kalmayıp, insan ilişkileriyle kültürünü de dönüştürerek, şeyleştirmektedir. Bu sayede gelenek ve geleneğe dayalı yaşam biçimleri yok edilmekte ve şeyleşen-metalaşan imgeler aracıllı̆ı̆yla yaşam deneyimlerimiz kökten değişime uğramaktadır. $\mathrm{Bu}$ sonucun toplumsal açıdan en belirgin tezahürüyse gündelik yaşam içinde gömülü gerçeğin kavranmasının artık daha güç olmasıdır. Benjamin'e göre (Aktaran: Oskay, 1981a; 4) modern dönem, geleneksel dönemden şu temel özellikleriyle ayrılmaktadır: "Teknik yetkinlik, kitlesel meta üretimi ve insan ilişkilerinin şeyselleşmesi” nedeniyle geleneğe dayalı yaşam biçimlerinin yok olması. Buna göre; geleneğe dayalı yaşam biçiminin yerini alan modern yaşam biçiminde imgelerin metalaşması, yaşam deneyimlerimizi de değiştirerek çok daha zor kavranabilir hale getirmiştir.

Modernleşme, geleneksel toplumlarda rastlandığı türden yüksek kültür ile alt kesimlerin tükettiği kültürden oluşan farklılaşmayı kitle sanatı içinde benzeştirmiş̧ir. Löwenthal'e göre kitle kültürü ile yüksek sanat ürünlerinin 
karş1l1klı ilişkisi; kültürel ürünlerin popülerleştirilmesi biçimde tezahür etmektedir. Yüksek kültür eserlerinin popüler hale gelmesiyse eserlerin içinde saklı gerçekle çelişkinin kaybolması ve eserin içeriğinin bozulması sonucunu yaratmaktadır. Böylece popülerleşen kültür ürünlerinin birey üzerinde yarattı̆̆1 fiili durum "acımasız realiteden kaçmakla birlikte irrasyonel bir otoriteye teslim olmak, kabullenmek" (Jay, 2005: 306) şeklinde gerçekleşmektedir. Yüksek kültür eserlerinin içeriğini bozan, değiştiren ve popüler hale getiren kitle kültürü; gerçekliğe yakın olma, kendiliğinden oluşma, demokratik ve kolektif bir çabanın sonucu üretilmiş olma" (Batmaz;1981;163) şeklindeki kendine has özellikleriyle geleneksel folk kültürünü de popülerleştirmektedir.

Kitle kültürü, tüm kültürel formların biçim ve içeriğini değiştirmekte ve bunlara yeni bir anlam kazandırmaktadır. Kültürel üretime nüfuz eden kültür endüstrisi, gerçek ve kendiliğinden bir kültür yerine içerik ve biçimine müdahale ederek nesneye dönüştürdüğü kalıplaşmış bir kültür üretmektedir. Modern sanatı benzer biçimde olumsuz içerikle algılayan Herbert Marcuse, kitle sanatını tek boyutlu sanat olarak nitelendirir. Geleneksel sanatın en olumsuz örneklerini bile içinde eritiyor olmasını yıkıcı doğasına bağlayarak, eleştirir. Bir kültürel ürün olarak -örneğin- müziğin "ticarileşmesi ve piyasa koşullarınca belirlenen alışveriş değeri” (Marcuse, 1997: 76) üzerinden tanımlanır hale gelmesi kitle kültürü bağlamında kültürel üretim ve tüketim süreçlerini tanımlamakta kullanılan metalaşma, şeyleşme ve fetişleşme kategorileri üzerinde daha fazla düşünülmesini gerekli k1lmaktadır. Kitle kültürünün büyük bir beceriyle kitle sanatı içine gömdüğü yüksek ve düşük sanat ayrımını silen "birleştirici” etki bir yana, fetişleştirdiği kültürel imgeleri dolaşıma sokarak, bunların "demokratik içeriğini bozmakta" (Jay, 2005: 312-313) ve yok etmektedir. Meta fetişizminin neden olduğu sosyolojik tezahürler on dokuzuncu yüz y1lın son çeyreğinden itibaren görülmeye ve başta "değişim değeri ve kullanım değeri” arasındaki dolayıma vurgu olmak üzere modern toplumların karmaşık yapısına ilişkin bir 
dizi açıklama girişimine konu edilmiştir. Bu maksatla kullanım değeri ile mübadele (değişim) değeri arasında kesin bir ayrım ortaya konmuştur (Marx, 1997;82); “ỉlk bakışta bir meta, ne olduğu belli, basit bir şey olarak görünür. Ancak metanın analizi, onun, metafizik inceliklerle ve teolojik süslerle dolu hayli karmaşık bir şey olduğunu ortaya koyar.” Bu dolayıma göre meta, elle tutulup gözle görülemeyecek kadar karmaşık özelliklere sahiptir. Marx'ın duyusal bakımdan algılanamayan niteliklerden bahisle metanın olgusal yanından ziyade duyusal yanına işaret etmektedir.

\section{Tüketim Toplumu ve Tüketim Kültürü}

Perhizcilik karşıtı hazcı (hedonist) yaşam tarzı modernliğin en belirgin görüngülerinden biridir. Modernleşme, hayatın erişilebilecek tüm mutluluğunun alınması, hayattan zevk duyulmasını sağlayacak her türlü eylemin gecikmeden ve ertelenmeden gerçekleştirilmesi konusunda bireyi hep yüreklendirmiştir. Modern toplumların işleyişinde birey; din, ahlâk ya da yurttaşlık bilinci üzerinden kisitlanmaz ve bireyi "zevk ve mutluluktan” (Oskay, 2001; 178) alıkoyacak herhangi bir telkinde bulunulmaz. Geleneksel toplumlara özgü perhizci etik ile modern topluma özgü hazcı etik arasındaki gerilimin tüketim üzerinden tanımlanıyor olması, modernleşmenin bireyi yeniden biçimlendirmekte ne kadar istekli olduğunu göstermektedir. Birey, yeniden biçimlendirilmektedir ancak bireyin dünyayı algılama biçimi de aynı kalmamıştır. Modernleşmeyle birlikte yapay yollarla üretilen imgeler ve kitle iletişim araçları kullanılarak tüketim hayata dâhil edilmeye çalışılmaktadır. Bu durumda birey, yapay bir kültür tarafindan kuşatıldığı imgeler ortamında hayatını "piyasanın kurallarına uyarak ama özgürlügünü yitirerek” (Benjamin, 1990; 48) usul usul tüketmektir. Tüketim kültürü ile tüketim toplumunun erken dönem örneklerine ilişkin geçmiş; iki yanında şık dükkânlarıyla üstü kapalı pasajlar, malların sergilendiği büyük vitrinleriyle mağazalar, binlerce ziyaretçisiyle panayır eğlenceleri, yeni yeni düzenlenmeye başlanan uluslararası 
fuarlar ve hali vakti yerinde olanlar için seyahat seçeneklerinin sunulmaya başladığı kent imgelerinden oluşan on dokuzuncu yüzyıla kadar uzanmaktadır. Benjamin, on dokuzuncu yüzyılın ikinci yarısından itibaren değişen toplumsal ilişkileri Baudelaire (Benjamin, 1993; 95-177)'in şiirleri üzerinden çözümlerken benzer tüketim alışkanlıklarınca yeniden inşa edilen modern toplum ve kent imgelerinden bahsetmektedir. Baudelaire şiirlerinde modern toplum tarafından belirlenen benzer ilişkiler, benzer kalabalıklar ile zenginlik ve yoksulluğun yan yanalığını içinde barındıran imgelerle dolu karmaşık kent tasviri Paris ile tamamlanmaktadır. Paris ile birlikte şiire giren modern kent ve modern topluma ilişkin görüngülerde; içi kumaşlarla kaplı dizi dizi mağazalar, gösterişli sokak lambaları, geniş caddeler ve kalabalıklar bulunur. Benjamin, değişen ilişkiler tarafından belirlenen yeni bir toplum ve kent yaşamını şiirinin esas konusu haline getiren bir şair üzerinden modernleşme tarihini ve modern toplumu kavramaya çalışmıştır. Bu kavrayışta, Baudelaire şiirleri üzerinden kenti tahlil etmeye ve modern toplumun değişen ilişkilerine "flâneur-yürür gezer” gözünden bakma çabası baskındır. On dokuzuncu yüzyılın kent görüngüsünde tüm ürünler ve insanlar tıpkı flâneur gibi sürekli bir dolaşım halinde bulunmaktadır. Aslında flâneur, yeni aydın-sanatçı tipinin bir tezahürüdür ve modernleşme tarafindan içinde bulunmaya zorlandığ 1 sanat piyasasında kendisine alıcı aramaktadır. Flâneur'un toplumsal ölçekte önemi, tüketime çağırılan modern toplumun bir parçası olması yanı sıra modern kentin mobilize edilmiş, hareket halindeki figürlerinden biri olmasından kaynaklanmaktadır. Benjamin, ürünlerin dolaşıma sokulduğu ve düşlerin maddeleştiği modern kentte büyük mağazaların “flâneur”a kalan son sığınak olduğunu düşünmektedir. Bu bağlamda Benjamin tarafindan sıkça kullanılan “düşlerin maddeleşmesi” (Benjamin; 1993, 94-95) metaforu oldukça önemlidir. Zira Benjamin tarafından sıkça tekrarlanan geleneksel toplumlara özgü "aura-hale" kaybı, modern topluma büyülü bir ortam olarak sunulan büyük 
mağazalar, mağazalarda sergilenen binlerce çeşit ürün ve tüm bunların hepsi anlamına gelen dönemin tüketim bağlamı tarafından tamamlanmaktadır. Eğlence ve tüketimin belirlediği büyülü atmosfer tarafından kuşatılan bireyin yaşadığı deneyimi bir tür fetişleşme olarak kavrayan Benjamin, on dokuzuncu yüzyılın ikinci yarısından itibaren yaygınlaşan dünya fuarlarını metanın hac yerleri olarak nitelendirmektedir. Ürün kadar ürünün sergilenme biçimleri ve ürünün dolaşım ve dağıtım olanaklarının da mükemmelleştiği fuarlarda ziyaretçilerin tüketim arzuları harekete geçirilebilmektir. Benjamin, on dokuzuncu yüzyıl modernleşmesini "düşlerin maddeleşmesi, aura kaybı ve kutsallığın yitirilmesi” tanımlarıyla kavramaktadır. Modernleşme, geleneksel toplumu ve kutsallığını maddileştirirken mağazalarda sergilenen ürünlerin büyülü yapay atmosferinden faydalanmaktadır. Modernleşme sonrası toplum ise yitirdiği değerleri yerine yapay düzenlemeler koymaya çalışmaktadır. Endüstriyel üretimin yok ettiği ormanların acısını, şehir merkezinde kurulan park ve birkaç ağaçla hafifletmeye çalışmak, kayıp gerçeklerin yerine yapay düzenlemelerin geçmesini beklemektir; "saf ve temiz bir görünüme sahip olmak isteyen her şey karşıtına dönüşür.” (Baudrillard, 1998: 39).

Tüketim bağlamı içinde değerlendirilmesi gereken bir diğer kategori modadır. Moda; değişiklik duygusuna olan ihtiyaç, süslenme merakı ve öykünme içgüdüsünden beslenerek biçimlenmekte ve verili olan güzel ile özdeşleşme arzusuyla yeniden üretmektedir. Modanın özünün kavranabilmesi toplumsal ilişkilerin neden ve sonuçlarının doğru saptanabilmesine bağlıdır. Kente ve modernleşmeye dair bir kategori olarak moda "cinsel çekiciliğin kullanılması, tüketim arzularının harekete geçirilmesi ve fetişleşme" (Benjamin, 1987; 9596) bağlamında ele alınmaktadır. Moda ve reklâm ilişkisi toplumsal olmak yerine sahte bireycilik içeren olumsuz yanı nedeniyle moda tarafından belirlenen beğeniler çerçevesinde kuşatılan birey, başkalarının giyim-kuşam özelliklerini takip ve taklit etmek zorunda kalmaktadır. Bu bağlamda düşük 
gelir grubuna mensup bireylerin, mahalle pazarından alınan taklit ürünleri kullanmaları "sınıf atlama arzusu" (Crane; 2010) ile açıklanmakta ve satın aldığı markanın aracılığıyla birey kimlik inşa etmektedir. Özendirme yoluyla yaratılan toplumsal standartlaşma; popüler kültür ve kitle kültürünün belirlediği standart tüketim davranışlarını mekanik hale getirerek toplumsal nüfuz alanlarını korumakta, güçlendirmektedir. Örneğin gösterilen ürün üzerinden vaat edilen "farklı olma ve farklılaşma" reklâmların içeriğine gömülerek, sunulmaktadır. Oysa reklâmın vaat ettiği farklılık aslında yoktur zira ürünün seri üretiminin doğasında aynılaştırma bulunmaktadır. Ürünün ne kadar çok reklâmı yapılıyorsa o denli türdeş kılma gücüne ulaşmaktadır. Bu durumu; "bireyin narsizmi ayrıksılığın hazzı yerine, kolektif niteliklerin kırılıp yayılması" (Baudrillard, 1997; 107) şeklinde tanımlamaktadır. Tüketiminin kamçılandığ1 ve metanın fetiş durumuna getirildiği bir dönemde moda aristokrasiye has ilgi alanı olmaktan çıkarak sokaklara yayılmıştır. Oysa her geçen gün dolaşım ve dağıtım olanakları artan ve daha çok üretilerek evrenselleşen metanın ömrü, moda nedeniyle her geçen gün daha da kısalmaktadır (Aktaran; Oskay, 1981b: 13). Moda, çeşitliliği artırılmış malların bu kez çekiciliğini artırarak meta fetişizmini tamamlamaktadır. Malın çekici yanları çoğunlukla pazarın doğasından kaynaklanmaktadır ve "şiirsel bir üslupla" (Benjamin, 1993, 150) sunulmaktadır. Şiirsel üslup, kutsallarını kaybetmiş modern toplumun tüketim güdülerini hedef almakta ve toplumu, tüketimin büyülü atmosferine davet etmektedir. Üslup, kaybedilen kutsal (aurahale) yerine kimi zaman mistik bir örtü altında, kimi zaman şiirsel bir ahenkle, kimi zaman cinsel çekicilikle birlikte kullanılmaktadır.

Birey ile tüketim arasındaki ilişki bireyin gerçek ihtiyaçlarından daha fazlasını arzu etmesi ve daha fazlasına yönelmesiyle birlikte kültürel ve sosyal bir içerik kazanmaktadır. Tüketim kültürü, ihtiyaçlarının farkında olan bireyin faydalanacağ1 ürünü satın almasıyla tamamlanan bir süreçten daha fazla, daha 
karmaşık ve daha fazla olgunun belirlediği kültürel bir süreçtir. Değişen üretim ve tüketim biçimleri nedeniyle karmaşıklaşarak kültürel bir süreç haline gelen tüketim kültürü geleneksel toplumlara özgü "alıcı ile satıcı" şeklinde basitçe kodlanan taraflardan daha fazlasına sahiptir. Üretim ve tüketim ilişkilerinin değişmesi sonucu tezahür eden tüketim kültürü, geleneksel toplumların tüketim pratiklerine nazaran çok boyutlu ve çok daha karmaşıktır. Bu nedenle tüketimin sadece ekonomik içeriği bulunmayıp, kültürel bir içerik de kazanmaktadır. Buna göre (Fromm, 2002: 49-50); On dokuzuncu yüzyllda çalışma, biriktirme ve tasarruf yüceltilirken, yirminci yüzyılda tüketim arzusunun serbest birakılması ve harcama özendirilmiştir. Yirminci yüzyıldan başlayarak artarak yerleşen anlayışa göre birey artık tüketim ilişkileri üzerinden tanımlanmaktadır. Bu bağlamda modern toplumdan üretim ve tasarruf yerine tüketim ve haz beklenmektedir (Bauman, 1999a: 93). Robert Bocock'a göre kültürel ve sosyal bir pratiğe dönüşen tüketim, içinde bir dizi sembol ve imge barındırmaktadır. Ancak imgeler, ürün ile tüketici arasında doğrudan ilişki kurulmasını sağlayan bilgilendirme içermezler. Aksine ürün üzerinden tüketici ile tüketim arzuları arasında bağ kurmayı amaçlamaktadır. Birey üzerine giyeceği giysi ya da üzerine oturacağı koltuğu satın alması halinde kazanacağı statü ve saygınlığa imgeler aracılığıyla inandırılmaktadır. İmgelerin sahte pırıltısı, sahip olunması halinde ürünü, bireyin hayatını değiştirecek büyülü bir nesneye dönüştürmektedir. Böylece tüketimi sürekli aktif kılan süreci oluşturan tarafların bir yanında idealize ettiği sosyal statüden beslenen arzularıyla birey, diğer yanındaysa ürünün arzu nesnesi haline getirilmesi bulunmaktadır (Bocock, 1997: 13).

Tüketim kültürü, bireyin gerçek ihtiyaçları yerine, statü elde etme ya da kabul görme arzularını harekete geçirerek tüketim çarkını çevirmektedir. İmgeler aracılığıyla yapılan göndermeler tüketilerek kimlik inşa edilmektedir. Tüketim kültürü; bireyin üretim ve tasarruf üzerinden tanımladığı değerler dizisi yerine, 
tüketim ve harcama üzerinden tanımladığı değerler dizisinden oluşmaktadır. Bauman'ın tüketim kültürünü tanımlarken kullandığı "olumlayarak, yüceltme" (Bauman, 1999a: 93) yaklaşımı benzer biçimde toplumsal kabul süreçlerinden beslenmektedir. Burada üretim ve tasarrufun birer erdem olduğu, bireyin daha fazla çalışıp üretmesi için istekli kılındığı geleneksel paradigmanın yerine tüketimin odağa alındığı, bireyin daha fazla tüketmesi için özendirildiği yeni bir paradigma tarif edilmektedir. Erich Fromm'un oldukça karamsar bakış açısına göre böylesine kökten bir paradigma değişimi ancak "tüketimin bir meziyet sayıldığ1 yirminci yüzyılla birlikte sömürü ve pasifliğe mahkûm edilmiş insanları tüketime koşullayarak” $(1996: 14,41)$ gerçekleştirilebilir.

Diğer yandan Fromm'un yirminci yüzy1l vurgusu, tüketim kültürünün toplumsal ilişkiler içinde önem kazanması ve bireyin tüketim üzerinden yeniden tanımlandığı kritik eşik, Fordist Üretim Yöntemi’ne işaret etmektedir. Ford otomobil fabrikalarının sahibi Henry Ford, 1914 yılından başlayarak Dearborn (Michigan) kentindeki fabrika montaj hattında çalışan işçilere sekiz saat çalışma karşılığında beş dolar ücret tarifesiyle bir dizi yeni iş ve emek örgütlenmesi içeren uygulamalar başlatmıştır. Ford'un ortaya koyduğu uzak görüşlülük, otomobil fabrikasında işletmeye açılan montaj hattı kadar önemli toplumsal değişimlerin başlatıcısı olabilmiştir. David Harvey’e göre Ford; emek süreci alanında aslında eski teknolojiler ve var olan iş bölümü rasyonalizasyonundan öte bir şey yapmamıştır. İşin yerinden kıpırdamayan işçiye akmasını sağlayan düzenlemeler sayesinde üretkenlikte muazzam artışlar elde edilebilmiştir. Ancak Ford'un asıl ayırt edici yanı; kitle üretimine karş1ık kitle tüketimi sayesinde varılan yeni estetik ve psikolojik eşiğin "rasyonelleştirilmiş, modernist, popülist ve yeni bir tür demokratik toplum" (Harvey, 1999; 147148) yaratmış olmasından kaynaklanmaktadır. Fordist üretim ve tüketim çerçevesinde ortaya çıkan rasyonelleştirilmiş modern toplumla birlikte üretimden tüketime kayan paradigma değişimi ve üretimin gözetim ve 
denetiminden tüketimin gözetim ve denetimine evirilen yirminci yüzy1l kapitalizminin doğasını yaratmıştır. Üretim bağlamında ortaya konan emek arzı, istihdam, üretimin maddi koşullarıyla nerede ve nasıl yapılacağı konuları yerini tüketicilerin neyi, ne kadar ve nasıl tüketeceğiyle ilgilenmektedir. Böylece Baudrillard'ın kavramsallaştırmasıyla toplumsal iş (ödev) konumuna evirilen tüketim eylemi, tüketicinin neden ve nasıl olduğuna karar veremediği bir süreç olması nedeniyle eylemin öznesinin yabancılaşma içinde tüketime zorlanmasıyla sonuçlanmaktadır. Bu durum, sürekli ihtiyaçları üzerinden uyarılan yeni bir insan tipi yaratmıştır. Fromm'a göre yeni insan sürekli olarak daha fazlasını tükettiği sürece makbul kalabilmektedir (Fromm, 1986: 16). İhtiyaç dâhilinde olsun ya da olmasın tüketim eyleminin sürekli k1lınabilmesi tüketici eğilimlerinin ölçülebilir hale getirilmesiyle mümkündür. Bauman'a göre on dokuzuncu yüzyıl modern toplumu ile yirminci yüzyıl modern toplumu arasındaki en büyük fark "harcama-tüketim” (Bauman, 1999b: 50) alışkanlıkları üzerinden belirlenmektedir. Buna göre on dokuzuncu yüzy1l toplumu; tasarruf ve yatırımın yüceltildiği değerler dizgesi üzerinden tanımlanırken, yirminci yüzyıl toplumu harcama ve tüketimin yüceltildiği değerler dizgesi üzerinden tanımlanmaktadır.

\section{Sonuç}

Kitle kültürü, kültür endüstrisi, tüketim kültürü ve tüketim toplumu bağlamında on dokuz ve yirminci yüzyılı anlama çabalarının eleştirel uğrağında yer alan Frankfurt Okulu tarafindan ortaya konan görüş ve açıklamalar önemli bir yer tutmaktadır. Özellikle yirminci yüzyılın ikinci yarısıyla birlikte modernleşmenin bir tezahürü olarak modern toplumun gündelik tüketim pratikleri, Frankfurt Okulu'nun başlıca ilgi alanını oluşturmuştur. Bu sayede tüketim, tüketim toplumu ve tüketim kültürüne ilişkin detaylı ve sistematik çözümlemeler ilk kez ortaya konabilmiştir. Buna göre; tüketim kültürü, yarattığ1 sahte bireysellik ve yönlendirilebilir tercihler yaratarak "birey ve demokratik 
toplum" üzerinde büyük bir tehlike potansiyeline sahiptir. Tüketim kültürü, birey üzerinde bulunan "ilgi uyandırma, statü öykünme, tazelik-yenilik" (Belk, 1988; 145) benzeri vaatler kullanarak işaret edilen ürüne yönelik arzu duyulmasını sağlamak üzere kurgulanmaktadır. Böylece mutluluk ile doğrudan ilişkilendirilen ihtiyaç duyulan ürünün satın alınması yerine ihtiyaç olsun ya da olmasın o ürünü satın alma eylemi haline gelmektedir. Tüketim kültürü, bireyin mutluluğunu basitçe satın alma eylemi ile sınırlandırarak içeriğini bozmakta ve popülerleştirmektedir (Fromm, 1986: 90). Umberto Eco'ya göre kitle iletişim araçlarının sahiplik ilişkileri iletişim araçlarının toplum üzerinde bilinç oluşturma işlevleri konusunda sahip olduğu güç nedeniyle oldukça önemlidir. $\mathrm{Bu}$ nedenle "bir ülkenin gerçek sahibi, o ülkedeki kitle iletişim araçlarını kontrol edenlerdir" (1991; 93) yargısında bulunan Eco ile benzer biçimde başta Frankfurt Okulu üyelerinde olmak üzere yirminci yüzyılı anlama çabaları kapsamında radyo, televizyon ve sinemanın "arzu nesnesi" yaratma konusundaki güç, beceri ve etkisi bağlamında kaygılar bulunmaktadır. Örneğin Benjamin'in modern kitle iletişimine ilişkin "sadece sanat yapıtı için değil, bir filmde izleyicinin önünden geçen manzara için de (benzer şeyler) geçerlidir” $(2000 ; 67)$ şeklindeki önermesinde, kültür endüstrisinin neden olduğu kurgusal yapay gerçekliğe dikkat çekmektedir. Buna göre sinemada bir dizi eylem izleyiciye aygıt aracılığıyla sunulurken bir tür optik testten geçirilmektedir. İzleyiciyle oyuncunun özdeşleşmesini sağlayacak biçimde kurgulanan film kareleri pek çok öğeyle oynanmakta, dekor ve 1şıklandırma gibi etkenlerle oyun kurgulanabilir parçalar haline getirilmektedir. Yirmi birinci yüzyılda sinema ve televizyon gibi güçlü imgeler üren kitle iletişim araçlarında kurgu, dekor, 1şıklandırma gibi pek çok öğe tarafından tamamlanan büyülü atmosferi nedeniyle geleneksel toplumlara özgü kutsal törenlerin yerini almış olduğu ve kendi efsanelerini yarattığını düşündürmektedir. 
Frankfurt Okulu kuramcılarına göre yüzyıllar boyunca efsane ve dogmalarla kuşatılan insanoğlunu akıl ve bilimin yardımıyla kurtaran aydınlanma ideali, bir süre sonra yarattığı kendi efsaneleriyle kuşattığı insanoğlunu daha önce hiç bilinmeyen yeni bir teslimiyet ve tahakküme zorlamıştır (Larrain, 1995: 80-81). Aydınlanma idealinin yarattığı modern efsaneler kültürel imgelerden oluşmaktadır. Kültürel imgelerin kuşattığı modern bireye kalan şeyse, içinde yaşadığı tüketimin toplumuna tam anlamıyla dâhil olmaktır. Baudrillard, tüketim toplumunda alış veriş pratiğinin bireysel doyum yerine toplumsal bir ödev olarak kurumsal hale getirilişini, merkezinde tüketimin bulunduğu yeni bir lisan üzerinden sorgulamaktadır; "bireysel hazlar ve ihtiyaçlar bu dile bağlı olarak sözden ibarettir" (Baudrillard, 1997: 88-90). Yirminci yüzyıl modern toplumu; üretim biçiminin değişmesiyle doğrudan bağlantılı olarak yaşamın odağına satın alma ve harcama eylemlerini koyduğu tüketim üzerinden tanımlanmaktadır. Tüketimin olumlanması ve özendirilmesi amacıyla maddi ihtiyaçlar kadar fantazyalara da sirayet eden geniş yelpazede tüketim kültürünü besleyen meta ve imgeler üretilmektedir. Tüketim kültürünün kuşatıcısı olduğu atmosfer üretim ve dağıtım süreçlerine meşruiyet kazandırmakla birlikte bireyin fantazyalarına hitap ettiği imgeler aracılığıyla tüketime yönelik güdüleme işlevi görmektedir. Böylece modern tüketici bireyliğinin sınırlarını ekonomik sistemin kendisine biçtiği rol bağlamında belirlemektedir. Bireyin satın alma eylemiyle tanımlanan tüketim çerçevesi; gündelik hayatı kapsamakla kalmayıp, imgeler ve göndermeler aracılığıyla fantazyalara da sirayet edecek şekilde geniş bir deneyim haline gelmektedir.

Baurdrillard'ın tüketim toplumuna ilişkin keskin tezlerini doğrularcasına 27 Eylül 2001 günü ABD eski başkanlarından George W. Bush, Chicago O’Hare havaalanında yaptığı bir konuşmada, ABD'nin küresel gücünü koruyabilmesini yurttaşların "seyahat etme ve eğlenme" pratiklerine sadık kalabilmeleri koşuluna bağlamıştır. 11 Eylül sonrası küresel savaşa giren bir ülkenin başkanı 
olarak Bush, yurttaşlarından tasarruf etmelerini ya da ülke kaynaklarını korumalarını istememiştir. Alışıldığı üzere yurttaşların daha çok çalışmalarını ya da askeri üretime katkı koymalarını da istememiştir. Yurttaşlarından "uçmalarını" ve "eğlenmeye" (https://georgewbush-whitehouse.archives) devam etmelerini isteyen Bush, üretim yerine tüketimin, tasarruf yerine harcamanın yüceltildiği bir lisan kullanmayı tercih etmiştir. Buna göre Amerikan yurttaşları, havayollarını kullanarak seyahat etmeli, Disneyland'a giderek eğlenmelidir. Ancak bunları yaparken mutlaka para harcamalı ve tüketim çarkının dönmesine katkıda bulunmalıdır. Bush'un basitçe talep ettiği "uçma ve eğlenme" eylemlerinde cisimleşen Amerikan hayat tarzını koruma çabasının önemi, gündelik yaşam pratiği içinde tüketimin bir doyum aracı ya da basitçe bir serbest zaman etkinliği olmak yerine krizden kurtuluş reçetesinde talep edilen yurttaşlık ödevi haline getirilmesinden kaynaklanmaktadır. Tüketim kültürü bağlamında bireyin özendirildiği deneyimler, perhizci ahlak ile hazc1 ahlak anlayışlarında bulunan karşıtlığı aşacak şekilde ideolojik bir içerik kazanmaktadır. Çalışmak yerine tüketmenin, tasarruf etmek yerine harcamanın olumlandığı tüketim kültürü lüks ile mutluluğu, ülke sevgisi ile yurttaş ödevini bir arada tanımlayan geniş bir anlam çerçevesi kazanmaktadır.

ABD başkanı George W. Bush'un 2003 yılında yaptığı konuşmada "küresel savaşa hazırlanan bir ülke" liderince yurttaşlarına hatırlatılan "ödev olarak tüketim" vurgusu dikkat çekicidir. 2011 yılı Ağustos ayında Londra'nın kuzeyinde bulunan Tottenham bölgesinde beş gün süren ayaklanma ve yağma hareketlerine ilişkin Britanya başbakanı David Cameron'un parlamentoda yaptığ1 açılamadaysa, tüketim kültürünün modern birey üzerindeki kuşatıc1 "ahlaki yaptırımlarına" vurgu yapılmıştır (açıklamanın geniş çaplı tam metni için bakınız: http://www.bbc.com/news/uk-politics-14492789). Tottenham bölgesi, genel olarak Britanya gelir ve kazanç piramidinin en altında bulunan işsiz ve evsiz İngilizler ile göçmenlerin yoğun olarak ikamet ettikleri suç 
oranları oldukça yüksek varoş bölgesi olarak bilinmektedir. Polis şiddeti ve bölge sakinlerinden birinin öldürülmesi nedeniyle sosyal medya üzerinden örgütlenen küçük bir grubun protesto gösterileri çok geçmeden yaygınlaşarak, şiddetlenmiş ve yaklaşık on beş bin kişinin katıldığı kitlesel bir ayaklanmaya dönüşmüştür. Beş günlük olayların bilançosunda; beş ölüm, yüzlerce yaralanma, binlerce tutuklama ile iki yüz milyon avro civarında ekonomik kayıp bulunmaktadır. Beş gün süren olaylar ve alınan önlemlere ilişkin Britanya Başbakanı David Cameron tarafından yapılan 11 Ağustos 2011 tarihli parlamento konuşmasında "İnsanlara saldırıldı, kamu binaları ile araçlar kundaklandı, sokaklar yerle bir edildi ancak en büyük felaket parası ödenmeden dükkânların yağmalanmasıydı." şeklindeki sözlerinin hedefinde ayaklanmaya dönüşen protesto gösterilerinde verilen resimlerde sıkça karşılaşılan camları kırılmış alışveriş merkezlerinden alınmış elektronik eşyaları taşıyan protestocular bulunmaktaydı. 2011 Londra olayları ile Başbakan Cameron tarafından olaylara ilişkin parlamento açıklamasının tüketim kültürü açısından iki önemli sonucu bulunmaktadır. İlki, yağmalama görüntüleri ile olayların katılımcılarını doğrudan ilgilendirmektedir. Buna göre, işsiz ve göçmenlerden oluşan protestocu kitlenin mevcut gelirleriyle asla sahip olamayacağı pahalı ürünlere duydukları tüketim arzusunun yağmalamayla tezahür ediyor olmasıdır. Ortaya çıkan yağmalama olayları, tüketim kültürünün kuşatıcı atmosferinin protestocu kitle üzerinde tüketim arzularının tatminine yönelik basitçe kriminal davranışlara neden olmasıdır. Adalet ve firsat eşitliği talebi ile başlayan protestoların, tüketime duyulan arzunun esas motivasyon kaynağı haline gelerek yağmalamaya dönüşmesi, tüketim kültürünün toplumun tüm katmanlarınca paylaşılan etkisinin en somut göstergesidir. Britanya Başbakanı Cameron tarafından "en büyük felaket" olarak tanımlanan yağmalama olaylarına ilişkin açıklamaysa tüketimin kültürünce tüketiciye yönelik konulan normatif kurallara gönderme yapmaktadır. Buna göre protestocular tarafından alışveriş 
merkezlerinden sökülüp, yağmalanan eşyalar parası ödenmediği için felakete neden olmuştur. Başbakana göre tüketim, bir yurttaş için "ödev” olmakla birlikte yurttaşa karşıllğını ödemek gibi "sorumluluklar" da yüklemektedir. Tüketime ilişkin ödev ve ahlaki sorumluluklara işaret eden somut olaylar ve politik açıklamalar, tüketim kültürünün toplumsal yaşamın birçok faktörle "bir birlikte belirleyeni” olmaktan çok daha fazla anlam içerdiğini göstermektedir.

\section{KAYNAKÇA}

Adorno Theodor, "Kültür Endüstrisi-Kültür Yönetimi", Çevirenler: Nihat Ünler, Mustafa Tüzel, Elçin Gen, İstanbul, İletişim Yayınları,2014.

Adorno Theodor, Horkheimer Max, "Aydınlanmanin Diyalektiği-Felsefi Fragmanlar-I", Çeviren: Ŏguz Özügül, İstanbul, Kabalcı Yayınları, 1995.

Adorno Theodor, Horkheimer Max, "Aydınlanmanın Diyalektiği-Felsefi Fragmanlar-II", Çeviren: Oğuz Özügül, İstanbul, Kabalcı Yayınları, 1996.

Batmaz, Veysel, "Popüler Kültür Üzerine Değişik Kurumsal Yaklaşımlar" AITİA İletişim Dergisi, Sayı:1, 1981.

Baudrillard, Jean, "Sessiz Yiğınların Gölgesinde ya da Toplumsalın Sonu”, Çeviren: Oğuz Adanır, Ayrıntı Yayınları, İstanbul, 1991.

Baudrillard, Jean, "Tüketim Toplumu”, Çevirenler: Hazal Deliçayll, Ferda Keskin, İstanbul, Ayrintı Yayınları, 1997.

Baudrillard, Jean, "Simulakrlar ve Simulasyon”, Çeviren: Ŏguz Adanır, Doğu Batı Yayınlart, İstanbul, 1998.

Bauman, Zygmunt, "Küreselleşme Toplumsal Sonuçları", Çeviren: Abdullah Yılmaz, Ayrıntı Yayınları, İstanbul, 1999 a

Bauman, Zygmunt, "Çalışma, Tüketicilik ve Yeni Yoksullar”, Çeviren: Ümit Öktem, Sarmal Yayınları, İstanbul, 1999 b 
Belk, Russell W, "Possesions and the Extended Self," (in) Journal of Consumer Research, Volume 15/12, 1988.

Benjamin Walter, "Pasajlar”, Çeviren: Ahmet Cemal, İstanbul, Yapı Kredi Yayıları, 1993.

Benjamin Walter, “Moda Üzerine”, Çeviren: Ahmet Cemal, Gergedan-1, 1987. Bocock, Robert, "Tüketim”, Çeviren: İrem Kutluk, Dost Kitabevi, Ankara, 1997.

Bottomore, Tom, "Frankfurt Okulu”, Çeviren: Ahmet Çiğdem, Ankara, Vadi Yayınlarl, 1997.

Crane, Diana, "Moda ve Gündemleri: Giyimde Sinlf, Cinsiyet ve Kimlik", Çeviren: Özge Çelik, Ayrıntı Yayınları, İstanbul, 2010.

Dolu, Şükrü, "Medya ve Tüketim Çılgınlı̆ğ” Düşünen Adam Yayınları, Ístanbul, 1993.

Eco, Umberto, "Göstergebilimsel Bir Gerilla Savaşına Doğru-Enformasyon Toplumu Efsanesi (içinde)”, Çeviren; Yusuf Kaplan, Rey Yayınları, İstanbul, 1991.

Fromm, Erich; "Yeni Bir İnsan-Yeni Bir Toplum”, Çeviren: Necla Arat, Say Yayınlarl, İstanbul. 2002.

Harvey, David, "Postmodernliğin Durumu”, Çeviren: Sungur Savran, Metis Yayınlar, İstanbul, 1999

Golding Peter, Murdock Graham, "Culture, Communicatıons and Political Economy in Mass Media and Society” Oxford University Pres, New York, 2000. Jay, Martin, “Diyalektik İmgelem”, Çeviren: Ünsal Oskay, Belge Yayınları, Istanbul, 2005.

Larrain, Jorge, "İdeoloji ve Kültürel Kimlik”, Çeviren: Nur Domaniç, Sarmal Yayınları, İstanbul, 1995. 
Lunn, Eugane, "Marksizm ve Modernizm" Çeviren: Yavuz Alogan, Alan Yayılarl, İstanbul, 1995.

Marcuse, Herbert, “Tek Boyutlu İnsan”, Çeviren: Aziz Yardıml, İstanbul, İdea Yayinlart, 1997.

Marx Karl, "Kapital”, Çeviren: Alaattin Bilgi, Sol Yayınlarl, Ankara, 1997.

Oskay, Ünsal, "Yıkanmak İstemeyen Çocuklar Olalım”, Yapı Kredi Yayınları, Istanbul, 2001.

Oskay, Ünsal, “Benjamin'de Tarih, Kültür ve Fantazya Anlayışı”, Oluşum, S:43, 4-5, 1981a.

Oskay, Ünsal, "Sanatın Modern Döneme Girişinde Charles Baudelaire ve Direnimci Modernizmi (II)", Oluşum, S-50, 4-19, $1981 b$.

https://georgewbushwhitehouse.archives.gov/news/releases/2001/09/200109271 .html (Erişim Tarihi: 02.11.2017)

http://www.bbc.com/news/uk-politics-14492789 (Erişim Tarihi: 02.11.2017) 